\title{
CONSTRUÇÃO DE PRÁTICAS DIDÁTICO-PEDAGÓGICAS COM ORIENTAÇÃO CTS: IMPACTO DE UM PROGRAMA DE FORMAÇÃO CONTINUADA DE PROFESSORES DE CIÊNCIAS DO ENSINO BÁSICO
}

\author{
STS Oriented didactic and pedagogic practices construction: \\ contribuition of an Elementary School \\ Science in-service program
}

\author{
Celina Tenreiro-Vieira \\ Rui Marques Vieira ${ }^{2}$
}

\begin{abstract}
Resumo: No quadro da atual reorganização curricular do Ensino Básico português, salienta-se a idéia de que o ensino das ciências deve ser visto, acima de tudo, como promotor da literacia científica. Nesse sentido, a perspectiva CTS deverá constituir o eixo integrador e globalizante da organização e da aquisição de conhecimentos e do desenvolvimento de capacidades de pensamento. Mas qualquer inovação, reforma ou reorganização curricular obriga a equacionar a formação de professores, enquanto a questão central da inovação curricular residir sobretudo no que os professores vão fazer das orientações curriculares para o ensino das ciências na sala de aula. Neste artigo, pretende-se dar conta de um estudo desenvolvido com a finalidade de descrever e analisar os contributos de um programa de formação continuada de professores na construção de práticas CTS. Dos resultados obtidos, concluiu-se que o programa de formação contribuiu para que os professores envolvidos promovessem práticas didáticopedagógicas com orientação CTS.
\end{abstract}

Unitermos: práticas didático-pedagógicas; Ciência-Tecnologia-Sociedade - CTS; Programa de Formação Continuada; professores de ciências do Ensino Básico.

Abstract: In the present scenario of the Portuguese Elementary Teaching Curriculum Reorganisation, the idea that science teaching should be looked at as a promoter of literacy becomes increasingly pertinent. In this sense, the STS perspective integrate and globalise knowledge acquisition and develops thinking skills. Nevertheless, any innovation, reformation or curriculum reorganisation forces the re-consideration of the teachers' formation, since the core question of curriculum innovation concerns the use that teachers make of the curriculum guidelines for science teaching in the classroom. This paper aims to give an account of a study developed with the intention of describing and analysing the contribution to an in-service program for science teachers of the construction of STS practices. It is possible to conclude, from the results, that the in-service Program was a good contribution, for the teachers involved, and promoted didactic and pedagogic STS oriented practices.

Keywords: didactic and pedagogic practices; Science-Technology-Society education; in-service program; Elementary Science teachers.

\footnotetext{
${ }^{1}$ Professora doutora em Didática das Ciências do Instituto Piaget de Viseu, Portugal. E-mail: cvieira@viseu.ipiaget.org.

${ }^{2}$ Professor doutor em Didática das Ciências do Instituto Piaget de Viseu, Portugal. E-mail: rvieira@viseu.ipiaget.org.
} 


\section{Introdução}

À semelhança do ocorrido em diversos países, em Portugal, a atual reorganização curricular da educação em ciências no Ensino Básico, recomenda que o ensino das ciências deve, acima de tudo, promover a literacia científica. Atingir a meta da literacia científica implica que os alunos possuam uma base substancial de conhecimentos científicos, bem como capacidades de pensamento que lhes permitam continuar a aprender, a realizar-se no campo pessoal e profissional e a lidar eficazmente com preocupações sociais. Esta meta entronca diretamente numa orientação Ciência-Tecnologia-Sociedade (CTS), pois esta visa o desenvolvimento de uma cidadania responsável, no âmbito de competências pessoais e sociais que permitam aos cidadãos lidar com problemas de aspecto científico-tecnológico.

Desenvolver práticas de ensino das ciências com uma orientação CTS obriga a equacionar a questão da formação de professores, enquanto "a questão central da inovação curricular não é tanto a construção de novos currículos, ainda que relevante, mas sobretudo o que os professores dele vão fazer" (CACHAPUZ, 1997, p. 145) em termos das ações de sala de aula. A formação de professores deve ser considerada fundamentalmente por duas razôes: 1) o currículo enunciado exige mudança de mentalidades e, como tal, importa que haja adesão por parte destes; e 2) os próprios professores reconhecem que não sabem como integrar a orientação CTS no ensino das ciências (DORI \& HERSCOVITZ, 1999; PRIETO, GONZÁLEZ \& ESPAÑA, 2000). Congruentemente, estudos sobre as práticas de sala de aula continuam a mostrar que o ensino das ciências está sobretudo centrado na transmissão de informação factual, desprezando as capacidades de pensamento (DORI \& HERSCOVITZ, 1999; TENREIRO-VIEIRA, 1999).

Dentro desta perspectiva, este estudo centrou-se no fomentar e apoiar os professores, por meio de um processo de formação pela investigação, na construção de práticas consistentes com uma orientação CTS para o ensino das ciências. O foco particular é o desenvolvimento, implementação e avaliação de materiais didáticos de cariz CTS no quadro de um trabalho conjunto e partilhado entre os investigadores principais e os professores colaboradores. $\mathrm{O}$ estudo visou, ainda, saber a opinião dos professores colaboradores sobre o processo de formação pela investigação experimentado/vivido.

\section{Enquadramento teórico}

O estudo assentou em duas idéias-base interligadas e interdependentes. Uma delas está ligada a dinâmicas atuais de inovação ou reorganização curricular da Educação em Ciências, com referência a metas e a orientações preconizadas. A outra tem a ver com a concretização prática de orientações emergentes do currículo intencional. Assim, ao fazerse a fundamentação teórica e na realidade educativa portuguesa, dá-se conta dos principais fundamentos relativamente à Educação em Ciências, à ação educativa do professor de ciências e à sua formação em contexto de inovação ou reorganização curricular.

Reconhecendo a necessidade de diminuir a defasagem entre o tipo de preparação que a escola fornece e aquele que a sociedade exige, desde a década de 1990, diversos países têm desenvolvido movimentos de reforma da Educação em Ciências. Tais movimentos sublinham insistentemente que a meta da Educação em Ciências deve ser a preparação de alunos cientificamente literados para que possam participar no processo democrático de tomada de decisóes e na resolução de problemas pessoais e sociais que envolvem a ciência e a tecnologia (MANZANO, MEMBIELA, HERMIDA \& PAZOS, 2000; SANTOS, 2001). A ênfase que tem sido 
atribuída à literacia científica nesta mudança de milênio deve-se, por um lado, à velocidade em que se produzem as novas revoluções científicas e, por outro, à incidência que a ciência e a tecnologia têm na configuração de uma cidadania responsável capaz de atuar com poder na recondução de movimentos sociais (GARCÍA, MARCO-STIEFEL \& ORCAJO, 2000).

Num mundo em constante mudança, cada vez mais dominado pelos produtos da ciência e da tecnologia, a literacia científica habilita as pessoas a usar informação científica e formas de pensar que informam a tomada de decisão pessoal (NATIONAL RESEARCH COUNCIL [NRC], 1996). Além disso, de acordo com este organismo, qualquer pessoa precisa usar informação científica e capacidades de pensamento para participar ativa e responsavelmente de uma sociedade democrática. Defende-se, ainda, que a literacia científica é um componente importante no mundo do trabalho e, conseqüentemente, no crescimento econômico em um quadro de cidadania efetiva e responsável.

$\mathrm{Na}$ opinião de alguns autores, como Prieto e outros (2000), a meta da literacia científica entronca diretamente numa orientação do ensino das ciências em torno de contextos (CTS). Isto porque uma orientação CTS para o ensino das ciências ao advogar a aquisição de conhecimentos científicos e o desenvolvimento de capacidades de pensamento e de atitudes a propósito da abordagem de assuntos e problemas em contexto real, isto é, a propósito de problemas sociais que envolvem a ciência e a tecnologia, cria condiçôes para que tais aprendizagens se tornem úteis no dia-a-dia, não numa perspectiva meramente instrumental, mas sim numa perspectiva de ação (CACHAPUZ, PRAIA \& JORGE, 2000; SOLVES \& VILCHES, 2000). Tanto mais que, a abordagem de conteúdos científicos a propósito de assuntos sociais de reconhecida relevância, como a saúde e o ambiente, dá-lhes significado e torna-os mais compreensíveis para os alunos (DORI \& HERSCOVITZ, 1999), aumentando assim a probabilidade de que não se tornem conhecimento inerte. Além disso, a abordagem de assuntos e problemas sociocientíficos ao levantar, de um modo concreto, a questão das relaçóes entre a Ciência, a Tecnologia e a Sociedade, permite, pela motivação e reflexão que suscita, compreender melhor o papel da ciência na sociedade e ainda o modo como a sociedade influencia os objetos de estudo da ciência e da tecnologia, bem como aprofundar os conhecimentos nos domínios científico e tecnológico e desenvolver capacidades de pensamento (MARTINS, DIAS \& SILVA, 2000). Isso possibilita a tomada de decisão mais informada e racional e o agir responsavelmente na esteira de uma ética de responsabilidade social (RAMSEY, 1993).

Neste quadro e a título ilustrativo, lembramos que, nos Estados Unidos da América, documentos baseados na reforma da Educação em Ciências, como o "Science for All American" (AMERICAN ASSOCIATION FOR THE ADVANCEMENT OF SCIENCE [AAAS], 1989), o "Benchmarks for Science Literacy" (AAAS, 1993) e o "National Science Education Standards" (NRC, 1996), ao estabelecerem que todos os alunos devem atingir literacia científica, perspectivam o ensino das ciências num contexto CTS. Efetivamente, a meta da literacia científica - que implica não só a aquisição e compreensão de conhecimento científico e tecnológico, mas também o desenvolvimento de capacidades de pensamento - está estreitamente ligada à utilização do conhecimento em questões pessoais e sociais. Está também relacionada com a compreensão das relaçôes entre a ciência e a tecnologia, bem como da forma como influenciam a experiência humana, a qualidade de vida e o progresso social e econômico. Está ainda ligada à necessidade de o indivíduo ser capaz de lidar com conceitos científicos e de usar capacidades de pensamento num contexto de cidadania responsável para, por exemplo, se pronunciar inteligentemente sobre questões públicas que envolvem a ciência. 
Em Portugal, a posição assumida em documentos que orientam a atual reorganização curricular do Ensino Básico (Decreto-Lei no 6/2001; ME-DEB, 2001) reflete também a meta da literacia científica embasada numa orientação CTW para a Educação em Ciências. Isto, porque a crescente importância do conhecimento científico exige uma população cientificamente literada, ou seja, uma população com capacidades e compreensão suficientes para entender e seguir debates científicos e envolver-se nas questôes que a tecnologia coloca, quer para eles como indivíduos quer para a sociedade como um todo. Nesta conjuntura, o ensino das ciências deve, pois, fomentar o desenvolvimento de competências (entendidas como um conhecimento em ação que integra conhecimentos, capacidades de pensamento e atitudes e valores) por parte do aluno, que lhe permitam enfrentar as mudanças e participar de uma sociedade democrática onde as decisões pessoais e políticas ligadas à ciência e à tecnologia não são isentas de valores por envolverem, muitas vezes, interesses econômicos e sociais (GALVÃO et al., 2000).

Tais competências, segundo o mesmo documento, não se coadunam com um ensino científico compartimentado em conteúdos desligados da realidade. Ao invés, a interação Ciência-Tecnologia-Sociedade deverá constituir uma vertente integradora e globalizante da organizaçăo e da aquisiçăo dos saberes científicos. Portanto, em oposiçăo ao conhecimento meramente acadêmico, divorciado do mundo exterior à escola, assume-se um ensino com uma orientação CTS. Tal orientação, valorizando o cotidiano para um ensino contextualizado, procura contribuir para uma melhor educação para a cidadania responsável.

Mas, toda esta renovação curricular coloca o problema da concretização prática. $\mathrm{Na}$ verdade, um aspecto é reconhecer e legitimar um conjunto de orientaçôes em termos de competências e situaçôes de aprendizagem a proporcionar aos alunos. Outro aspecto, bem diferente, é levá-los à prática, concretizando-os no âmbito da ação educativa na escola, em geral, e na sala de aula, em particular. Contribuir para efetivar um ensino das ciências segundo uma orientação CTS, tendo em vista atingir a meta da literacia científica, exige que se trabalhe com os professores para que possam enfrentar os novos desafios com confiança, segurança e iniciativa (PRIETO et al., 2000). Na verdade, assumir que os professores são profissionais capazes de identificar e interpretar problemas educativos e procurar soluçóes para esses problemas, no quadro de orientaçôes curriculares nacionais (ME-DEB, 2001), obriga a um olhar para a formação de professores que configure uma formação pela investigação, num trabalho conjunto e partilhado entre e com os professores de modo a interligar inovação/investigação/formação (CACHAPUZ, 1997). Trata-se de usar a formação como um processo de pesquisa pelo qual a produção de conhecimentos seja reinvestida na ação educativa (BRONSON, 1995; CANÁRIO, 1991; MCINTYRE, 1995; ZEICHNER \& GORE, 1995).

Num contexto de trabalho colaborativo com os professores, encarar a prática didático-pedagógica como um ponto de partida, caracterizando as orientaçōes em de sala de aula mediante a construção de materiais didáticos (FITZSIMMONS \& KERPELMAN, 1994; LAKERVELD \& NENTWING, 1996), cria condiçôes para introduzir com poder inovaçōes desejadas. Isto porque quanto maior for a consciência do professor relativamente às origens e consequiências das suas práticas, maior será o seu poder de intervenção e transformação, quer das práticas, quer dos constrangimentos existentes (ZEICHNER, 1983). Além disso, a reflexão sobre as práticas, tendo como referência o currículo intencional, viabiliza a tomada de consciência da necessidade da mudança. Tal como sublinham Gess-Newsome \& Lederman (1995), as oportunidades para o professor refletir sobre as práticas de sala de aula e identificar mudanças a fazer influenciam o seu conhecimento de ensino, tornando-o mais conhecedor, versado ou perito. 
Assumida a necessidade da mudança, importa colaborar com o professor no sentido de o ajudar, por um lado, a reconhecer que a mudança é possível e, por outro, a formar uma representação coerente da inovação pretendida. Isso é fundamental para a procura de respostas tendo em vista o gerir a congruência entre as intençóes e as ações de sala de aula (FELDMAN \& ATKIN, 1995). O envolvimento dos professores na procura de respostas, pela pesquisa, ajuda-os a acentuar a idéia de que a teoria e a prática são mutuamente constitutivas (HURSB, 1995). Simultaneamente, cria-se oportunidades para os professores fundamentarem opções e decisões e para continuamente construírem e reconstruírem as bases teóricas e práticas do seu ensino.

Sendo assim, integrar os professores que vivem o seu cotidiano profissional na escola, em equipes de investigação, abre possibilidades para que estes colaboradores rasguem novos horizontes, procurando e esforçando desenvolver práticas de ensino mais de acordo com os referentes que colhem da e na investigação desenvolvida (CACHAPUZ, 1997). Neste contexto, os investigadores principais/facilitadores podem e devem cuidar para que os professores colaboradores sintam apoio, acompanhamento e retroação, o que é fundamental para que novas práticas sejam interiorizadas e implementadas (LOUCKS-HORSLEY, HEWSON, LOVE \& STILES, 1998; SPARKS \& LOUCKS-HORSLEY, 1990; SPARKS, 1983; JOYCE \& SHOWERS, 1980, 1996).

\section{Metodologia}

Este ponto inclui quatro seções. $\mathrm{Na}$ primeira, apresenta-se o desenho de investigação do estudo. Na segunda, descreve-se o processo formativo. Na terceira, foca-se o processo de coleta de dados. Na última menciona-se o tratamento dos dados.

\section{Desenho do estudo}

Tratando-se de um projeto orientado para apoiar os professores a desenvolverem práticas consistentes com uma orientação CTS para o ensino das ciências por um processo de formação pela investigação, o estudo segue uma metodologia de investigação-ação. Pois, tal como enfatuam Pedretti \& Hodson (1995), a investigação-ação é a abordagem mais viável e coerente para focar as questões do currículo em ação, as quais no presente estudo se configuraram como sendo centrais à implementação da orientação CTS para a Educação em Ciências. Em acréscimo e como sublinha Noffke (1995), a investigação-ação encerra um duplo potencial em ajudar os professores a procurar alternativas para as suas práticas atuais. Pois que, ao serem envolvidos em grupos de investigação-ação os professores, em vez de simplesmente desejarem e esperarem que as suas práticas sejam eficazes, começam a saber se o são ou não e o porquê.

Efetivamente, a coleta de dados e de evidências relacionadas com a prática ajuda o professor no processo contínuo de identificar contradições. Tal contribui para localizar espaços de ação estratégica, tendo em vista gerir a congruência entre as suas intenções e as ações de sala de aula (FELDMAN \& ATKIN, 1995). Além disso, o envolvimento dos professores em grupos de investigação-ação ajuda-os a acentuar a idéia de que a teoria e a prática são mutuamente constitutivas (HURSB, 1995), enquanto a teoria ou o como se conceitualiza a escolaridade, o ensino e a aprendizagem influencia e é influenciado pela prática.

Nesta base, o grupo de investigação-ação envolveu dois investigadores principais/facilitadores (IP/Fs) e três professoras colaboradoras (PCs) do Ensino Básico (primeiro ciclo, o qual inclui alunos dos 6 aos 10 anos) que ao serem contactadas pelos IP/Fs mostraram 
interesse e disponibilidade para integrar o grupo. Estas professoras trabalhavam em diferentes escolas do mesmo distrito.

Seguindo de perto o trabalho de Pedretti \& Hodson (1995), os investigadores principais/facilitadores (IP/Fs) assumiram papéis como: 1) catalizador da mudança e do crescimento pessoal/profissional; 2) facilitador/mediador; 3) compilador de informação do grupo; 4) uma fonte de apoio; 5) uma pessoa de recurso; e 6) uma fonte de inquérito.

\section{Desenvolvimento do processo formativo}

O percurso formativo desenvolveu-se em três fases articuladas. Passa-se a descrever cada uma destas fases com referência aos propósitos, às sessões, atividades e estratégias de formação usadas, bem como aos recursos utilizados e/ou produzidos.

\section{1a Fase}

A primeira fase do percurso teve como propósito refletir sobre as teorias, práticas, crenças e ações dos professores, com especial ênfase naquelas que se prendem mais diretamente com a abordagem CTS para o ensino das ciências. Nesse sentido, num primeiro momento procurou-se estimular a partilha de experiências e vivências e a reflexão sobre as ações de sala de aula, bem como sobre as razões que embasam tais ações. No contexto da reflexão sobre as práticas didático-pedagógicas, as PCs foram solicitadas a darem conta de recursos usados, assim como estratégias e atividades de ensino/aprendizagem que habitualmente propunham aos seus alunos. Foi-lhes ainda pedido que explicitassem as razóes subjacentes a tais escolhas.

Tendo por base a visão das professoras sobre as suas ações de sala de aula e das suas ideias acerca do ensinar e aprender ciências, promoveu-se a discussão em torno da questão: Pontos de convergência e de divergência entre as práticas didático-pedagógicas desenvolvidas e as orientações curriculares para o ensino das ciências no Ensino Básico no quadro da reorganização curricular em curso. A realização desta atividade de discussão levou, por um lado, à tomada de consciência, por parte das PCs, de que pouco conheciam sobre as atuais orientações para o ensino das ciências no Ensino Básico e, por outro, fomentou o desejo de saber mais acerca do assunto de forma a, nomeadamente, averiguar a concordância existente entre as suas práticas (currículo implementado) e as idéias veiculadas e defendidas no quadro das novas orientações curriculares (currículo intencional).

Com base na leitura e discussão de documentos que enquadram o Currículo Nacional, (ME-DEB, 2001) foram discutidas as suas ideias principais quanto a princípios orientadores, finalidades/papel das ciências no Ensino Básico e situações de aprendizagem enfatizadas. Evidenciada a presença de uma orientação CTS para o ensino das ciências, foram aduzidas e discutidas razões justificativas para tal. A este nível, a leitura e a reflexão sobre o conteúdo de artigos sobre o assunto, de autores como Membiela (1995, 2001), Acevedo-Díaz (1995; 2001), e Cachapuz et al. (2000) viabilizou a apropriação de um conjunto de razões sobre a importância de, na Educação em Ciências, desenvolver práticas didático-pedagógicas com uma orientação CTS.

$\mathrm{Na}$ esteira do defendido por autores como Aikenhead (1998), de forma a viabilizar a apropriação e a compreensão do que se entende por educação CTS, foram propostas atividades de formação de apresentação de informação, leitura e discussão de documentos acerca de teorizações sobre a educação CTS. Deste modo, criaram-se oportunidades para (re)construção de idéias, mediante a negociação de significados, acerca da educação CTS e, ao mesmo tempo, o estabeleceu-se uma base de entendimento comum. 
Além disso, foi feita referência a quadros teóricos, abordagens e projetos CTS, o que ajudou a estabelecer e visualizar potenciais respostas à questão "como orientar o ensino das ciências numa perspectiva CTS?". Nesse sentido, foram também analisados materiais relativos a projetos CTS tais como o Projeto Satis e o Projeto Apqua. Na seqüência da leitura e discussão de informação e da análise de projetos CTS, procurou-se extrair e sistematizar um conjunto de princípios, linhas orientadoras e sugestões que ajudassem a desenvolver, de forma fundamentada, práticas didático-pedagógicas com uma orientação CTS.

\section{$2^{a}$ Fase}

A segunda fase centrou-se na construção e validação de materiais didáticos CTS para o ensino das ciências no Ensino Básico. Esta fase envolveu três momentos: 1) concepção e desenvolvimento de materiais didáticos em apoio ao ensino de um tema organizador de ciências de acordo com uma orientação CTS para o ensino das ciências; 2) implementação dos materiais desenvolvidos em contexto de sala de aula; 3) coleta de evidências sobre o impacto dos materiais desenvolvidos nas aprendizagens realizadas pelos alunos e avaliação dos materiais didáticos CTS desenvolvidos (tendo por base as evidências que foram sendo compiladas sobre o impacto dos mesmos nas aprendizagens realizadas pelos alunos).

\section{Concepção e desenvolvimento de materiais didáticos CTS}

No âmbito do primeiro momento (concepção e desenvolvimento de materiais didáticos CTS) da segunda fase do percurso formativo, começou-se por estabelecer o tema a trabalhar, levando-se em conta os interesses, gostos e preferências das PCs, bem como critérios de seleção de temas CTS, tais como: 1) serem adequados ao desenvolvimento cognitivo dos alunos; 2) serem importantes nos dias de hoje e na vida futura dos alunos; e 3) serem potencialmente do interesse dos alunos (MEMBIELA, 1997). Diante do exposto, optou-se por desenvolver mater iais didáticos CTS tendo por base o tema: "As plantas: sua utilização em atividades humanas". Esta temática foi perspectivada focando, entre outros, aspectos relacionados com a alimentação e com a agricultura. A este propósito abordaram-se questões/conteúdos como: contributos da Ciência e da Tecnologia para se conseguir uma alimentação suficiente e segura, contributos da Ciência e da Tecnologia para se obter um solo fértil mediante o uso de fertilizantes e vantagens e desvantagens, para os seres vivos, do uso de pesticidas e herbicidas na agricultura.

Selecionado o tema e mantendo presente o propósito de desenvolver materiais didáticos de caráter CTS em apoio ao ensino do mesmo, foram discutidas, negociadas e estabelecidas orientações a plasmar nos materiais didáticos a desenvolver. Assim, acordou-se: 1) ter em conta as idéias prévias dos alunos; 2) contextualizar a aprendizagem da ciência por meio da abordagem de situaçóes-problema onde a aprendizagem dos conceitos e dos processos surge como uma necessidade sentida pelos alunos para dar resposta a tais situações; 3) focar as interações Ciência-Tecnologia-Sociedade sempre que tal ajude os alunos a compreender o mundo na sua complexidade e globalidade; 4) apelar ao desenvolvimento de capacidades de pensamento, designadamente de pensamento crítico, possibilitando o agir racional e responsavelmente; 5) apelar ao pluralismo metodológico no âmbito das de estratégias de trabalho; e 6) envolver os alunos numa variedade de atividades em que são encorajados a construir e mobilizar conhecimentos e a usar capacidades de pensamento. A título ilustrativo, os alunos foram envolvidos na realização de atividades como: análise e resolução de situações-problema retiradas de contextos reais; análise de notícias e artigos de jornais e revistas de divulgação 
científica; atividades laboratoriais; debates sobre questões socialmente relevantes e que envolvem a ciência e a tecnologia e pesquisa de informação usando fontes de informação diversificadas.

Neste enquadramento, o caminho percorrido envolveu, primeiramente, a construção de um mapa conceitual sobre o tema "As plantas: sua utilização em atividades humanas", bem como a elaboração de um documento orientador do trabalho a desenvolver. Tal documento especifica os objetos de estudo e as competências a promover e descreve as situações de aprendizagem a propor aos alunos. Em seguida, construíram-se dois outros documentos, concretamente: 1) o "Caderno de atividades de aprendizagem", o qual inclui o material necessário à realização das diferentes atividades de aprendizagem; e 2) o "Guião do professor" que inclui sugestôes de atuação na orientação, exploração e discussão de cada atividade a ser realizada pelo(s) aluno(s) (em consonância com o documento "Caderno de atividades de aprendizagem"). Em anexo (Anexo A) encontra-se um exemplo de uma atividade de aprendizagem desenvolvida e realizada pelos alunos.

\section{Implementação dos materiais didáticos}

Os materiais didáticos CTS foram implementados, em contexto de sala de aula, pelas PCs. No decurso deste momento, os IP/Fs realizaram visitas às salas de aula das PCs, as quais constituíram oportunidades de iniciar observações de sala de aula e a escrita de relatórios pessoais. Dentro desta perspectiva, as professoras foram encorajadas a manter, ao longo do projeto, a elaboração de relatórios.

Os relatórios das PCs e dos investigadores foram sendo usados como fonte de discussão e reflexão sobre sentimentos, idéias e sobre as práticas didático-pedagógicas desenvolvidas nas sessóes/encontros conjuntos que simultaneamente foram sendo realizados.

\section{Avaliação dos materiais didáticos}

No decorrer e após a implementação dos materiais didáticos CTS, realizaram-se sessões de trabalho orientadas para a avaliação dos materiais didáticos produzidos. Nestas sessões as professoras apresentaram as suas idéias e perspectivas sobre as práticas desenvolvidas usando os materiais didáticos produzidos. Nestas sessões os IP/Fs procuraram fomentar a reflexão sobre a ação, mediante um questionamento provocativo, estimulando as PCs a avaliarem a congruência e a eficácia das suas açôes, a identificarem pontos fortes e menos fortes da sua atuação na exploração dos materiais didáticos desenvolvidos e a explicitarem o que podiam fazer de maneira diferente.

\section{$3^{a}$ Fase}

No quadro da promoção da qualidade dos materiais didáticos CTS produzidos, a terceira fase centrou-se numa reflexão sobre estes, tendo em conta os dados compilados para a avaliação dos mesmos em termos do impacto nas aprendizagens realizadas pelos alunos.

$\mathrm{Na}$ seqüência da reflexão conjunta realizada, foram introduzidas alterações pontuais em algumas das atividades integradas no documento "Caderno de atividades de aprendizagem”. Foram, também, efetuadas algumas modificações no "Guião do professor" relativamente às orientações para a condução e exploração de determinadas situações de aprendizagem de forma a potenciar respostas mais profundas e sistematizadas por parte dos alunos. 


\section{Coleta de dados}

Em relação às técnicas de coleta de dados, usaram-se diversas delas, como: a observação, o inquérito e a análise documental. Ao fazê-lo, reconhece-se a potencial utilidade de, numa abordagem qualitativa seguindo a metodologia de investigação-ação, recorrer a uma variedade de técnicas de coleta de dados de modo a completar a informação obtida e a aumentar a sua validade. Aliás, a triangulação, isto é, o uso combinado de diferentes técnicas de coleta de dados, é apontada por vários autores como Cohen \& Manion (1994), como uma prática muito útil enquanto permite combinar os pontos fortes e corrigir as deficiências de cada uma delas.

Quanto às observações realizadas, nomeadamente pelos IP/Fs, elas incidiram sobre as aulas das professoras colaboradoras. O "observador" assumiu, em diferentes momentos, papéis diversos nas atividades da turma tais como: apoio aos alunos e envolvimento na conversação com a professora colaboradora e com os alunos. Ao assumir tais papéis, cada um dos IP/Fs teve a oportunidade de estar mais perto das professoras colaboradoras e partilhar uma experiência comum (ANDERSON, 2000). Tal tornou-se importante para promover a reflexão e a introspecção sobre as práticas das professoras do grupo de investigação-ação. As notas de campo e os registos efetuados deram origem a relatórios pessoais dos IP/Fs que observaram tais práticas (relatos escritos).

No âmbito da técnica de inquérito, privilegiou-se a realização de entrevistas. Realizaram-se duas entrevistas individuais com cada professora colaboradora: uma no início do estudo, a qual pretendia elicitar informação sobre as seguintes dimensões: experiência inicial, atitudes/sentimentos sobre a profissão e o ensino das ciências e consumo informal de ciência; e outra no final do estudo, com a qual se pretendeu recolher opiniões sobre o percurso formativo e, particularmente, sobre o desenvolvimento dos materiais didáticos CTS.

No decorrer do estudo, foram também realizadas entrevistas, mais e menos formais, pelos IP/Fs, com o intuito principal de captar a perspectiva das professoras sobre os materiais didáticos com foco CTS. Considerando-se que a gravação de tais entrevistas não era desejável, uma vez que poderia inibir e perturbar as professoras e, por conseguinte, corresponder a um fator de enviesamento dos dados coletados, o seu conteúdo foi tão próximo quanto possível, reconstruído e registado por escrito pelo(s) investigador(es), dando origem a relatos escritos.

Os documentos analisados incluem materiais didáticos usados pelas professoras para serem realizados, pelos alunos, trabalhos e atividades de avaliação e ainda os relatórios pessoais dos IP/Fs bem como os relatórios elaborados pelas PCs.

\section{Tratamento dos dados}

$\mathrm{Na}$ análise dos dados usou-se predominantemente a técnica de análise de conteúdo. Esta análise foi feita recorrendo a procedimentos abertos ou exploratórios, onde decorreu a necessidade de múltiplas leituras dos dados, de forma a delinear categorias de análise. Isso implicou "trabalhar com os dados; organizá-los; procurar padrões e regularidades; dividi-los em categorias; sintetizá-los; descobrir o que é importante e o que deve ser comunicado" (BOGDAN \& BLIKEN, 1994).

Assim, numa primeira fase, procedeu-se à leitura e à análise dos dados relativos a cada PC e aos seus alunos. No decorrer da leitura analítica dos dados (procurando interpretar e tornar compreensíveis os dados colhidos), procurou-se colocar em evidência padróes, regularidades, bem como tópicos presentes nos dados. Nessa seqüência, estabeleceram-se categorias de análise dentro de cada domínio considerado. Concretamente, no domínio relativo ao 
impacto nos alunos, consideraram-se as seguintes categorias: 1) reação dos alunos às experiências de aprendizagem; 2) aquisição de conhecimentos; e 3) desenvolvimento de capacidades de pensamento. No domínio relativo ao impacto nas professoras, consideraram-se as categorias: 1) natureza da educação CTS no ensino das ciências; 2) desenvolvimento de materiais didáticos; 3) desenvolvimento pessoal/profissional; e 4) trabalho colaborativo.

Numa segunda fase, procedeu-se a uma análise transversal, procurando evidenciar mudanças nas formas de pensar e de agir das professoras colaboradoras e dos alunos (BOGDAN \& BLIKEN, 1994).

\section{Resultados}

O estudo teve como propósito apoiar os professores por meio de um processo de formação pela investigação, a implementarem práticas de ensino das ciências consistentes com uma orientação CTS. O foco particular foi o desenvolvimento, a implementação e a avaliação de materiais didáticos com foco CTS.

Nesta base, os resultados que surgem em seguida correspondem aos obtidos no contexto das duas primeiras fases do processo formativo anteriormente descrito. Assim, neste ponto começar-se-á por apresentar os resultados referentes ao impacto destes materiais nos alunos a que se destinavam. Nesta avaliação, ter-se-á em conta a reação dos alunos às experiências de aprendizagem que lhes foram proporcionadas e a consecução de propósitos em termos da aquisição de conhecimentos e do desenvolvimento de capacidades dos alunos.

Quanto ao impacto nas PCs, o estudo visa ainda saber a opinião destas sobre o processo de formação pela investigação desenvolvido. A este nível, as suas percepções iniciais e ao longo do percurso formativo são enquadradas em termos de: natureza da educação CTS no ensino das ciências; desenvolvimento de materiais didáticos; desenvolvimento pessoal/profissional e trabalho colaborativo.

\section{Impacto nos alunos}

Nesta seção, procura-se dar conta do impacto, nos alunos, da implementação dos materiais didáticos CTS desenvolvidos, tendo por base os dados que foram sendo colhidos ao longo das práticas didático-pedagógicas com estes materiais, no contexto de conversas informais e, ainda, os dados constantes em documentos compilados. Ao fazê-lo, têm-se em consideração as categorias de análise: reação dos alunos, aquisição de conhecimentos e desenvolvimento de capacidades.

\section{Reação dos alunos}

A reação dos alunos às primeiras atividades de aprendizagem com foco CTS que lhes foram apresentadas foi, por um lado, de alguma expectativa e, por outro, de receio, pois incluíam solicitações "muito diferentes do que costumavam fazer" (aluno da prof. A). Apesar disso, com o decorrer da implementação dos materiais didáticos e diante da diversidade de "trabalhos e coisas para pesquisar, sempre interessantes" (aluna da prof. A), os alunos foram vencendo medos e receios e envolvendo-se, com gosto e entusiasmo, na sua realização. De forma cada vez mais notória solicitavam "mais destas atividades, pois fica-se a saber muitas coisas sobre as plantas e também tem muita Língua Portuguesa” (aluno da prof. B). Um aluno da prof. A afirmou, em diferentes 
momentos, que "as aulas com estas atividades são muito mais divertidas do que com as do livro" [manual escolar adotado de Estudo do Meio].

Esta reação positiva foi se acentuando à medida que a implementação dos materiais didáticos CTS avançava. O envolvimento efetivo de todos os alunos, quer no trabalho individual, quer no trabalho coletivo foi uma constante.

As discussões/debates que se geraram a propósito de alguns dos assuntos foram, também, muito participadas. A este propósito, por exemplo, a prof. A comentou que os seus alunos se envolviam em "várias discussões até ao rubro".

Para além das atividades de discussão, os alunos reagiram muito positiva e entusiasticamente a atividades de pesquisa/inquérito e a atividades laboratoriais. A propósito de tais atividades fizeram comentários como "que bom, vamos fazer experiências" (aluno da prof. A), "que máximo, vamos investigar" (aluno da prof. B). A adesão dos alunos a estas atividades ficou bem patente também na quantidade e diversidade de documentos que compilavam em casa e traziam para a escola, incluindo informações extraídas da internet.

\section{Aquisição de conhecimentos}

Relativamente à temática das "plantas", os alunos revelaram possuir, desde o início da implementação dos materiais didáticos CTS, bastante idéias e opiniôes, embora muitas das idéias prévias que possuíam não fossem coerentes com o conhecimento aceito pela comunidade científica. As atividades permitiram elicitar estas idéias dos alunos sobre a referida temática e posteriormente a sua reestruturação. Foi neste sentido que foram desenvolvidas atividades, como algumas atividades laboratoriais, as quais proporcionaram o "conflito cognitivo".

A par da (re)construção de conhecimentos, os materiais curriculares ajudaram os alunos a usar de modo mais preciso a linguagem científica. De fato, progressivamente, foi-se verificando que, em várias discussóes, eram os próprios alunos que se corrigiam uns aos outros, usando expressões do tipo "não deves dizer assim" e "use termos mais corretos".

Os resultados obtidos na ficha de avaliação construída pelo grupo de investigação evidenciaram a compreensão e o uso de conhecimentos científicos e tecnológicos. Além do domínio da terminologia científica ligada às plantas, a maioria dos alunos foi capaz de relacionar os conhecimentos sobre as plantas com as atividades humanas, apresentando, por exemplo, razões para o uso de determinadas plantas (e não outras) na indústria têxtil e as razões e conseqüências do uso de algumas tecnologias na agricultura.

Diante do desempenho sucessivamente revelado pelos alunos no "domínio dos conhecimentos científicos (...) e da reação positiva de alguns pais sobre os trabalhos de casa" (prof. B), sobre esta temática, que os alunos desenvolveram, as PCs manifestaram a sua satisfação por estarem envolvidas no projeto e, conseqüentemente, terem tido oportunidade de desenvolver práticas com uma orientação CTS. A título ilustrativo, a prof. A, na entrevista final, relata que:

Nunca, ao longo destes muitos anos de serviço, senti que os alunos gostassem tanto deste assunto e revelassem uma compreensão tão profunda e útil para a vida deles, como a conseguida com estes materiais. (...) Os alunos aprendem com gosto e de uma maneira mais interessada e relacionada com a vida.

\section{Desenvolvimento de capacidades de pensamento}

Nas primeiras aulas com os materiais didáticos CTS, os alunos revelaram dificuldades em dar resposta às solicitações que exigiam o uso de capacidades de pensamento; a algumas questóes, não respondiam, e a outras, faziam de forma incongruente. "Eles (os alunos) têm 
dificuldades em ir além da primeira impressão. Como dizemos que têm de completar, ficam apreensivos, e se não os ajudarmos, muitos não são capazes de responder a estas primeiras questôes" (prof. B, no final da $3^{a}$ aula com os materiais didáticos desenvolvidos).

Constatou-se também que os alunos não estavam familiarizados com uma linguagem relativa às capacidades de pensamento; consultavam o dicionário ou questionavam a professora sobre o significado de termos como "hipóteses", "razões", "resumir", "semelhanças" e "diferenças".

Com o decorrer do trabalho proposto nos materiais didáticos CTS, os alunos tornam-se progressivamente mais confiantes, respondendo de modo cada vez mais aceitável às situações que apelavam a capacidades de pensamento. Com efeito, se se centrar a atenção numa das capacidades de pensamento presente em várias atividades, que é a de ser capaz de "apresentar razões" verifica-se, pelas respostas dos alunos, que estes foram revelando, progressivamente, maior domínio da mesma e o número de razões foi, inclusive, aumentando. Além disso, passaram a solicitar ao professor razóes para algumas das suas afirmações e a usar com mais freqüência o "porquê?".

Neste sentido, é possível afirmar que os materiais didáticos CTS desenvolvidos estimulam o uso de capacidades de pensamento dos alunos. As dificuldades iniciais, com o apoio das suas professoras, foram progressivamente vencidas. Nas últimas atividades integradas nos materiais didáticos CTS, os alunos respondem de forma eficaz às solicitações que exigem o uso de capacidades de pensamento. Por exemplo, na atividade "Investigando o uso de plantas nas tradições e costumes", os alunos, na sua globalidade, tendo em conta a análise das suas respostas, foram capazes de, autônoma e independentemente, delinear a investigação a realizar, explicitando: o foco/propósito da mesma, o que iam fazer, que fontes iam consultar (incluindo a internet) e como iam registar os resultados da sua investigação.

\section{Impacto nas professoras colaboradoras}

Nesta seção, procura-se dar conta do impacto, nas professoras, do processo de formação pela investigação em que colaboraram, tendo por base os dados que foram colhidos no contexto das observaçôes das práticas didático-pedagógicas com os materiais didáticos CTS, de entrevistas e de conversas informais e ainda os dados recolhidos com base na análise de documentos compilados. Ao fazê-lo, têm-se em consideração as categorias de análise: natureza da educação CTS no ensino das ciências; desenvolvimento de materiais didáticos; desenvolvimento pessoal/profissional e trabalho colaborativo.

\section{Natureza da educação CTS no ensino das ciências}

No início do estudo, para nenhuma das professoras a educação CTS surge como uma finalidade central na Educação em Ciências no Ensino Básico. De fato, em diversas situaçôes (entrevistas e conversas informais), quando questionadas sobre as tendências presentes no Currículo Nacional, as professoras responderam mencionando os conteúdos em termos de conhecimentos científicos a focar. Tendem a considerar que tal é o possível e o desejável, pelas exigências avaliativas e dos pais.

A análise do conteúdo de entrevistas e conversas informais mantidas com as PCs no início do processo formativo indicam que as PCs consideravam que as capacidades de pensamento estavam inerentes ao próprio processo de ensino-aprendizagem, pois os alunos para 
fazer algo tinham sempre que pensar. Congruentemente, os dados resultantes da análise de materiais didáticos que as PCs usavam antes de se envolverem no projeto, apontam no sentido de o desenvolvimento de capacidades de pensamento tender a não ser contemplado, pelo menos de forma explícita. Com efeito, um dos aspectos que ressalta é o fato de muitos dos materiais didáticos usados pelas professoras corresponderem a cópias de páginas de manuais escolares, nas quais surgem as conclusões da ciência que o aluno deve memorizar. Outro está ligado ao tipo de questões formuladas aos alunos. $\mathrm{O}$ mais freqüente corresponde às questôes a serem completadas, em que é deixado um espaço para o aluno preencher usando palavras ou símbolos. Um outro tipo bastante comum são as questôes de associação. Tais tipos de questôes favorecem, sobretudo, aprendizagens que se situam nos níveis mais baixos de taxonomias de objetivos educacionais, normalmente simples memorização de conhecimentos, o que não é consistente com uma orientação CTS.

As PCs, antes do processo formativo, não contemplavam explícita e intencionalmente a meta da literacia científica e particularmente a orientação CTS no processo de ensino/aprendizagem das ciências. Ante a ausência de formação, também não seria expectável que contemplassem explícita e intencionalmente tal meta nas suas práticas didático-pedagógicas. Efetivamente, uma das PCs mencionou que nunca havia tido formação sobre CTS. A título ilustrativo, a prof. B afirmou: "Não estava minimamente familiarizada com a educação CTS".

No seguimento de, no processo formativo, terem tido oportunidades de conhecer e compreender quadros teóricos, abordagens e projetos CTS, as professoras foram construindo idéias mais claras, profundas e consistentes sobre o assunto. As citações a seguir dão conta da mudança na visão das professoras sobre a orientação CTS.

A oportunidade de ter participado deste projeto contribuiu fortemente para ver que as minhas práticas podiam mudar sem que os meus alunos deixassem de ter melhor aproveitamento. Com estas atividades CTS os alunos mostraram-se muito mais interessados e participativos. (prof. A)

Depois de ter percebido o que realmente se pretende com esta mudança curricular nas ciências foi para mim muito importante experimentar com os meus alunos os materiais que se construíram e verificar que promovem mesmo as inter-relaçōes entre CTS e que os alunos, além de aprenderem mais e melhor, tornaram-se mais criticos e ativos. (prof. B)

Apesar do enorme trabalho tido com a produção dos materiais CTS, estes são, sem dúvi$d a$, de enorme qualidade para a abordagem deste tema de um modo mais agradável e interessante para os alunos do $5^{\circ}$ ano. Nunca os senti tão entusiasmados e motivados para as ciências como com estes materiais. (...) As minhas aulas foram, sem duivida, diferentes para melhor e sinto que estou mais próxima do que deve ser o ensino das ciências no Ensino Básico. (prof. C)

A análise dos dados compilados permite estabelecer um quadro em que se evidencia uma mudança progressiva nas práticas das PCs. Por exemplo, foi visível uma mudança na operacionalização de estratégias/atividades como o debate/discussão e o questionamento. Em vez de uma orientação quase exclusiva na aquisição de conhecimentos científicos, passaram a contemplar o explicitar das inter-relações da Ciência e da Sociedade e, por vezes, com a Tecnologia, e a apelar para as capacidades de pensamento.

O mesmo aconteceu com os recursos curriculares. De um número reduzido, especialmente o manual escolar e algumas fichas e cartazes elaborados pelas próprias professoras, passou a existir o recurso a outros materiais e suportes, como enciclopédias, computador (incluindo a internet) e outras fontes de informação, como os elementos do agregado familiar do aluno. 


\section{Desenvolvimento de materiais didáticos}

Antes do início do processo formativo propriamente dito, as PCs nunca tinham desenvolvido, individualmente ou em conjunto com outros colegas, materiais didáticos de cariz CTS e nem sabiam como fazê-lo. Nas várias conversas sobre as suas práticas, antes de se envolverem no processo formativo, foram assumindo que:

Não estamos habituadas a trabalhar em conjunto e muito menos para produzir materiais. (prof. $C$ )

Tenho muitas dúvidas sobre a qualidade da maioria dos materiais, incluindo os dos manuais escolares que temos ao nosso dispor, mas também não sei como mudar esta situação. (prof. A)

Apesar deste sentimento, após a primeira fase do percurso formativo, envolveram-se na construção de materiais didáticos com foco CTS a serem implementados na sua sala de aula. No início, as PCs tiveram dificuldade, por exemplo, em elaborar um mapa de conceitos sobre "as plantas", onde estivessem presentes explicitamente as inter-relações CTS. Mas as leituras feitas, as reflexões e sugestões dos IP/Fs, permitiram que se avançasse para a elaboração deste e de outros documentos (conforme descrito na seção relativa à segunda fase do desenvolvimento do processo formativo).

Este trabalho, amplamente discutido por forma a contemplar competências a fomentar nos alunos, foi evoluindo, algumas vezes com recuos, para a elaboração de cada atividade e sua seqüência no processo global de ensino/aprendizagem das ciências.

As PCs, na avaliação e reflexão sobre os materiais didáticos CTS desenvolvidos, fizeram apreciações que evidenciam as potencialidades educativas dos mesmos. Transcrevem-se, a seguir, alguns dos comentários feitos por elas.

Esta experiência de desenvolver e depois implementar os materiais foi para mim marcante. Considero que estes materiais, além das potencialidades a nivel CTS, são um bom exemplo do que se pode fazer nas escolas. Para isso é preciso ampliar experiências e formaçôes como esta à maioria dos professores. (prof. $B$ )

temáticas. (prof. C)

Além destes materiais [sobre as plantas] deviamos construir agora outros sobre as outras

As professoras consideraram que a segunda fase do processo formativo, relativa ao desenvolvimento dos materiais, foi fundamental para a melhoria das suas práticas didáticopedagógicas e teve resultados positivos do ponto de vista profissional e pessoal, como se descreverá em seguida.

\section{Desenvolvimento pessoal/profissional}

Como já ficou evidenciado por vários dos episódios e comentários das PCs, anteriormente apresentados, tudo aponta para que estas professoras, fruto do seu envolvimento no percurso, tenham tido desenvolvimento pessoal e profissional. As professoras colaboradoras fizeram uma apreciação bastante positiva desse processo, expressando um grau de satisfação muito bom diante do mesmo. Afirmaram que "no final desta experiência" muitas das suas necessidades de formação foram satisfeitas e o seu "bem-star" (prof. C) aumentou, dado terem sido construídas perspectivas e propostas concretas para a sala de aula. 
As PCs consideraram a sua colaboração no grupo de investigação-ação como muito boa e muito útil para refletir e atuar sobre as práticas de sala de aula. Estas afirmaram concretamente:

A formação e a oportunidade de ter ajudado a construir os materiais CTS contribuiu muito para me sentir profissionalmente preparada para cumprir as novas exigências curriculares que nos são feitas para uma Educação em Ciências que promova uma efetiva a literacia científica dos alunos do Ensino Básico. (prof. A)

Considero que estou mais bem preparada para enfrentar os desafios que o século XXI nos impõe a respeito da Educação em Ciências com uma orientação CTS. (...) Depois da implementação dos materiais didáticos que desenvolvemos, as minhas práticas nunca mais serão iguais ao que fazia. (prof. B)

No que se refere ao desenvolvimento pessoal as professoras, pese embora muitas das dúvidas que ainda revelam sobre a operacionalização do currículo ao nível dos projetos curriculares (de escola e de turma), mostraram-se mais satisfeitas e confiantes quanto ao processo de ensino/aprendizagem das ciências no Ensino Básico, nomeadamente quanto à orientação CTS. Uma dos professoras, neste sentido, afirmou:

Depois da confusão inicial que sentia, bem como a maioria dos professores das escolas, com mais uma mudança nos programas estou agora a sentir maior clareza e percepção sobre as razões de tal mudança. Sinto mais confiança agora. (prof. $C$ )

O desenvolvimento pessoal foi igualmente visível na aceitação deste novo conhecimento sobre a orientação CTS, bem como a gestão de sentimentos associados com a mudança nas suas atividades e crenças sobre o ensino das ciências. A promoção do desenvolvimento pessoal foi alicerçado na vida real de trabalho das professoras.

\section{Trabalho colaborativo}

As professoras consideraram muito importante as atividades de partilha e discussão de idéias e experiências, de apresentação e discussão de informação sobre a educação CTS e extremamente importante o trabalho colaborativo desenvolvido. Duas professoras referiram mesmo que devia ter sido dedicado mais tempo ao desenvolvimento de materiais didáticos, por forma a ser possível produzir materiais CTS, passíveis de serem usados pelos alunos, no âmbito de outras temáticas. A muita importância atribuída ao trabalho colaborativo no desenvolvimento de materiais didáticos ajuda a compreender o enorme envolvimento de todo o grupo de investigação-ação. Neste âmbito foi, também, valorizado o apoio e retroação recebidas, bem como o incentivo e estímulo para tentar, refletir e tentar de novo. Os materiais de apoio utilizados foram considerados pertinentes e bastante adequadas à apropriação e domínio da orientação CTS no ensino das ciências.

Outro aspecto realçado pelas PCs foi a satisfação por trabalharem num contexto caracterizado pela abertura de espírito. Uma das professoras referiu que "quando somos incentivados e apoiados a expressar o que pensamos, conseguimos um trabalho conjunto de qualidade, como é o caso dos materiais que já construímos" (prof. B).

\section{Conclusões e implicações}

No quadro da reorganização curricular do Ensino Básico português, salienta-se a idéia de que o ensino das ciência deve ser visto, acima de tudo, como promotor da literacia 
científica. Nesse sentido, a orientação CTS deve constituir o eixo integrador e globalizante do desenvolvimento de competências, quer de conhecimentos científicos e tecnológicos, quer de capacidades de pensamento e ainda de atitudes/valores.

Neste enquadramento, o projeto de investigação-ação realizado, centrado no apoiar os professores do Ensino Básico no desenvolvimento de práticas de ensino das ciências consistentes com uma orientação CTS, configurou-se como um processo formativo conjunto e partilhado entre e com as professoras, que vivem o seu cotidiano profissional na escola, de modo a interligar inovação/investigação/formação. Tratou-se de usar a formação como um processo de pesquisa por meio do qual a produção de conhecimentos fosse reinvestida na ação educativa.

Professoras colaboradoras e investigadores edificaram um trabalho de autêntica colaboração, criando espaços de partilha de informação, discussão de idéias e práticas. As professoras foram atribuindo sentido ao que significa ensinar ciências de acordo com uma orientação CTS.

Daqui decorrem algumas implicaçôes para a formação contínua de professores. Por forma a que as oportunidades de formação de professores possam reverter a favor da renovação e inovação, a colaboração entre professores e investigadores deve ser, uma realidade reconhecida e valorizada. No quadro da realização de um trabalho colaborativo assume relevância $\mathrm{o}$ atender às preocupaçōes, medos, incertezas e receios dos professores, ajudando-os a gerir tais sentimentos no sentido de não militarem contra a mudança. A par disso, importa construir quadros que evidenciam que a mudança é possível e desejável.

Investigadores e professores devem constituir comunidades de reflexão, onde o professor é sujeito ativo do seu desenvolvimento pessoal e profissional, assumindo o investigador um papel de animador e promotor da reflexão sobre as práticas e sobre a teoria que embasa as práticas.

Outro aspecto central do projeto configurou-se na produção e validação de materiais didáticos CTS para o ensino das ciências no Ensino Básico. A este nível, uma idéia a ressaltar é o fato das professoras colaboradoras continuarem (mesmo após o projeto) a usar os materiais desenvolvidos pelo grupo de investigação-ação. Importa também notar o desejo manifestado pelas professoras colaboradas em construírem, em conjunto com os investigadores, mais materiais didáticos CTS relativamente a outras temáticas.

Decorrente, por um lado, da escassez de materiais didáticos inovadores, a que os professores possam recorrer para utilizarem ou reestruturarem para o seu trabalho cotidiano, e, por outro, da relevância que os materiais produzidos no âmbito do presente projeto tiveram no desenvolvimento pessoal e profissional das professoras colaboradoras, é preciso incrementar a investigação focada na produção e validação de materiais didáticos CTS para a Educação em Ciências no Ensino Básico. É ainda crucial a publicação e divulgação de tais materiais.

\section{Referências}

ACEVEDO-DÍAZ, J. A. Educación tecnológica desde una perspectiva CTS: una breve revisión del tema. Alambique: Didáctica de las Ciencias Experimentales, n. 3, p. 75-84, 1995.

Cambiando la práctica docente en la enseñanza de las ciencias a través de CTS. Boletin del

Programa Ciência, Tecnologia, Sociedad e Innovación da Organizzação dos Estados Iberoamericanos-OEI, jun., 2001. Disponível em: <http://www.oei.es/ctsi15.htm>. Acesso em 15.set.2001. 
AIKENHEAD, G. STS science in Canada: From policy to student evaluation Disponível em: <http://www.usask.ca/education/people/aikenhead/stsincan.htm>. Acesso em: 18.set.2000.

AMERICAN ASSOCIATION FOR THE ADVANCEMENT OF SCIENCE. Science for all americans. Washington, 1989.

. Benchmarks for science literacy. Washington, 1993.

ANDERSON, G. Fundamentals of educational research. 2. ed. London: Falmer Press, 2000.

BOGDAN, R.; BIKLEN, S. Investigação qualitativa em educação: uma introdução à teoria e aos métodos. Tradução de M. J. Alvarez, S. B. Santos e T. M. Baptista. Porto: Porto Editora, 1994.

BRONSON, G. Putting the "p" into participation in government course. In: NOFFKE, S. E.; STEVENSON, R. B. (Ed.). Educational action research: becoming practically critical. New York: Teachers College Press, 1995.

CACHAPUZ, A. Ensino das Ciências e mudança conceptual: estratégias inovadoras de formação de professores. In: ENSINO das ciências. Lisboa: Instituto de Inovação Educacional, 1997.

CACHAPUZ, A; PRAIA, J.; JORGE, M. Reflexão em torno de perspectivas do ensino das ciências: contributos para uma nova orientação curricular: ensino por pesquisa. Revista de Educação, Lisboa, v. 9, n. 1, p. 69-79, 2000.

CANÁRIO, R. Mudar as escolas: o papel da formação e da pesquisa. Inovação, Lisboa, v. 4, n. 1, p. 77-92, 1991.

COHEN, L.; MANION, L. Research methods in education. 4. ed. London: Routledge, 1994.

DORI, Y. J.; HERSCOVITZ, O. Questions-posing capacbility as an alternative evaluation method: Analysis of an environmental case study. Journal of Research in Science Teaching, New York, v. 36, n. 4, p. 411-430, 1999.

FELDMAN, A.; ATKIN, J. M. Embedding action research in professional practice. In: NOFFKE, S. E.; STEVENSON, R. B. (Ed.). Educational action research: becoming practically critical. New York: Teachers College Press, 1995.

FITZSIMMONS, S. J.; KERPELMAN, L. C. The national perspective. In: (Ed.). Teacher enhancement for elementary and secondary science and mathematics: status, issues, and problems. Washington: National Science Foundation, 1994. 


\section{Celina Tenreiro-Vieira e Rui Marques Vieira}

GALVÃO, C. et al. Ciências: competências essenciais no Ensino Básico (documento de trabalho). Lisboa: Ministério da Educação/Departamente de Educação Básica, 2000.

GARCÍA, T. A.; MARCO-STIEFEL, B.; ORCAJO, T. I. Alfabetización científica: novos horizontes educativos. In: MARTINS, I. P. (Org.). O movimento CTS na Peninsula Ibérica. Aveiro: Universidade de Aveiro, 2000.

GESS-NEWSOME, J.; LEDERMAN, N. G. Biology teachers' perceptions of subject matter structure and its relationship to classroom practice. Journal of Research in Science Teaching, New York, v. 32, n. 3, p. 301-325, 1995.

HURSB, D. Developing discourses and stuctures to support action research for educational reform: Working both ends. In: NOFFKE, S. E.; STEVENSON, R. B. (Ed.). Educational action research: becoming practically critical. New York: Teachers College Press, 1995.

JOYCE, B.; SHOWERS, B. Improving inservice training: the message of research. Educational Leadership, Washington, v. 37, p. 379-385, 1980.

The evolution of peer coaching. Educational Leadership, Washington, v. 53, n. 6, p. 12-16, 1996.

KUMAR, D.; D. CHUBIN, D. (Ed.). Science, technology \& society education: a resource book on research and practice. New York: Kluwer Academic Press, 1998.

LAKERVELD, J.; NENTWING, P. Scholl-based inservice education. Educational Leadership, Washington, v. 53, n. 6, p. 68-71, 1996.

LOUCKS-HORSLEY, S. et al. Designing professional development for teachers of science and mathematics. Thousand Oaks: The National Institute for Science Education, 2001.

MANZANO, M. C. et al. Dos proyetos curriculares innovadores de ciencias orientadas hacia la relevancia social y personal. In: MARTINS, I. P. (Org.). O movimento CTS na Peninsula Ibérica. Aveiro: Universidade de Aveiro, 2000.

MARTINS, I. P.; DIAS, C. C.; SILVA, P. A Biologia no ensino secundário: tendências curriculares, trabalho laboratorial e interesses dos alunos. Revista de Educação, Lisboa, v. 9, n. 1, p. 169-185, 2000.

McINERNEY, J. D. BSCS and national standards: an affirmation and a challenge. In: BYBEE, R. W.; McINERNEY, J. D. (Ed.). Redesigning the science curriculum. Colorado Springs: National Science Foundation, 1995.

MEMBIELA, P. Ciencia-tecnología-sociedad en la enseñanza-aprendizaje de las ciencias experimentales. Alambique: Didáctica de las Ciencias Experimentales, n. 3, p. 7-11, 1995. 
. Una revisión del movimiento CTS en la enseñanza de las ciencias. In: (Ed.).

Ensenãnza de las ciencias desde la perspectiva ciência: tecnología-sociedad: formación científica para la ciudadanía. Madrid: Narcea Ediciones, 2001.

NATIONAL RESEARCH COUNCIL. National science education standards. Washington: National Academy Press, 1996.

NOFFKE, S. E. Action research and democratic schooling: problematics and potencials. In: NOFFKE, S. E.; STEVENSON, R. B. (Ed.). Educational action research: becoming practically critical. New York: Teachers College Press, 1995.

PEDRETTI, E.; HODSON, D. From rhetoric to action: implementing STS education through action research. Journal of Research in Science Teaching, New York, v. 32, n. 5, p. 463-485, 1995.

PORTUGAL. Ministério da Educação. Departamento da Educação Básica. Currículo nacional do Ensino Básico. Lisboa: Ministério da Educação, 2001.

PRIETO, T.; GONZÁLEZ, F. J.; ESPAÑA, E. Las relaciones CTS en la enseñanza de las ciencias y la formación del profesorado. In: MARTINS, I. P.(Org.). O movimento CTS na Península Ibérica. Aveiro: Universidade de Aveiro, 2000.

RAMSEY, J. The science education reform movement: implications for social responsability. Science Education, New York, v. 77, n. 2, p. 235-258, 1993.

SANTOS, M. E. A cidadania na "voz" dos manuais escolares: O que temos? O que queremos? Lisboa: Livros Horizonte, 2001.

SOLVES, J.; VILCHES, A. Finalidades de la educación científica y relaciones CTS. In: MARTINS, I. P. (Org.). O movimento CTS na Península Ibérica. Aveiro: Universidade de Aveiro, 2000.

SPARKS, D.; LOUCKS-HORSLEY, S. Models of staff development. In: HOUSTON, W. R. (Ed.). Handbook of research on teacher education. New York: MacMillan, 1990.

SPARKS, G. Synthesis of research on staff development for effective teaching. Educational Leadership, Washington, v. 41, n. 3, p. 65-72, 1983.

TENREIRO-VIEIRA, C. A influência de programas de formação focados no pensamento crítico nas práticas dos professores de ciências e no pensamento crítico dos alunos. 1999. 587f. Tese (Doutorado) Faculdade de Ciências, Universidade de Lisboa, Lisboa, 1999. 


\section{Celina Tenreiro-Vieira e Rui Marques Vieira}

ZEICHNER, K. M. Alternative paradigms of teacher education. Journal of Teacher Education, Washington, v. 34, n. 3, p. 3-9, 1983.

ZEICHNER, K. M.; GORE, J. M. Using action research as a vehicle for student teacher reflection: a social reconstructionist approach. In: NOFFKE, S. E.; STEVENSON, R. B. (Ed.). Educational action research: becoming practically critical. New York: Teachers College Press, 1995.

Artigo recebido em agosto de 2004 e selecionado para publicação em agosto de 2005 . 


\section{ANEXO A}

Materiais didáticos desenvolvidos - Um exemplo.

Atividade de aprendizagem

$\mathrm{O}$ uso de pesticidas e de fertilizantes na agricultura

1. Muitos agricultores, para aumentarem a produção de produtos agrícolas que cultivam, utilizam fertilizantes e pesticidas.

1.1. Na sua opinião, os cientistas e os tecnólogos que contribuíram para a invenção e aplicação dos pesticidas e fertilizantes são responsáveis pela aplicação que os agricultores fazem deles?

\section{Por quê?}

1.2. Na sua opiniāo, o uso de fertilizantes e pesticidas na agricultura é bom, mau ou bom e mau para a sociedade?

\section{Por quê?}

